\title{
Research on the Current Situation, Causes and Countermeasures of English Learning Anxieties of Chinese Students Studying Abroad
}

\author{
Gu Guannan
}

Taizhou Polytechnic College, Taizhou city, Jiangsu Province, China, 225300

Keywords: English learning anxieties, Chinese students studying abroad, Cross-cultural communication

\begin{abstract}
In the process of global integration, more and more Chinese students go abroad to study English. In the process of English learning, due to cultural, psychological, environmental and other factors, Chinese students are prone to anxiety. Based on the investigation of the English learning anxieties of Chinese students studying abroad, this paper analyzes the anxiety situation in the process of English learning, and discusses the coping strategies in order to reduce their anxiety and cultivate their English learning ability.
\end{abstract}

\section{Current Situation of English Learning Anxieties of Chinese Students Studying Abroad}

Anxiety is a universal phenomenon in human psychological life. Due to social changes and progress of the times, people are facing more pressure and challenges, so that people appear more anxious and more opportunities. Language learning anxiety is unique for students in the process of learning language, and its unique characteristics will produce a kind of emotional anxiety about beliefs, self-awareness, behavior and emotion in classroom language learning. In an early study of foreign language teaching mainly focus on intelligence and learning ability, later studies focus on affective factors such as motivation and attitude, now more and more researchers focus more on attention to anxiety affective variables, and the coping methods were discussed Chinese students think English is difficult to learn, have obvious anxiety exists in certain degree in the learning process, such as the students in Chinese classes reflect their restlessness, discomfort in the final exam. For groups of college students, the formation of this anxiety, not only affected by the college students' personality characteristics and learning activities, but also in the influence of teachers' teaching methods and teaching attitude, language environment, cultural atmosphere and other factors, showing a tendency to increase, restricting college students English learning motivation and learning effect. We investigate Chinese students studying abroad and obtain the following data:

Table 1. Current situation of English learning anxiety of Chinese students studying abroad

\begin{tabular}{|l|r|r|r|r|}
\hline & Mild anxiety & Moderate anxiety & Severe anxiety & No anxiety \\
\hline Listening & 12.3 & 40.2 & 35.1 & 3.9 \\
\hline Speaking & 15.2 & 33.9 & 29.6 & 12.6 \\
\hline Reading & 40.9 & 21.6 & 17.5 & 12.8 \\
\hline Writing & 30.7 & 40.7 & 15.9 & 6.8 \\
\hline
\end{tabular}

In order to reveal the forms and formation mechanism of foreign students' English learning anxiety, and find out the ways and methods to eliminate anxiety, this paper makes a systematic study of this problem through the form of investigation and analysis. We should fully understand the anxiety of foreign students in learning English, adopt the targeted measures to the students with English learning anxiety, reduce their anxiety to the minimum, and improve the teaching and learning effect.

\section{Causes of English Learning Anxieties of Chinese Students Studying Abroad}

According to the investigation, we find that there are mainly three causes resulting in the English learning anxieties of Chinese students studying abroad, which are Cultural Cause, Psychological 
Cause and Environmental Causes. The investigation data is shown as Table 2.

Table 2. Causes of English learning anxiety of Chinese

\begin{tabular}{|l|r|r|r|r|}
\hline Causes & \multicolumn{1}{|l|}{ Listening } & Speaking & Reading & Writing \\
\hline Culture & 25.2 & 41.5 & 30.2 & 15.8 \\
\hline Embarrassment & 30.3 & 27.6 & 22.9 & 32.8 \\
\hline Environment & 20.9 & 15.8 & 22.3 & 36.7 \\
\hline
\end{tabular}

\subsection{Cultural Cause}

In College English listening learning, good environmental factors can reduce students' anxiety, and their weak foundation is also an important reason for their psychological anxiety, these factors intertwined, affecting their English Listening Learning effect. Language competence is the most important issue for Chinese students in cross-cultural communication. Language ability refers not only to the differences in pronunciation and grammar, but also to the way in which language is used. This is the most difficult problem for Chinese students to communicate with each other in cross-cultural communication. For foreign students, compared to social language applications, the use of English language is relatively simple, but it is also a big challenge. Language is a complex system, which includes words, grammar, phonetics, semantics, the four subsystems. Learning language may not be difficult, but it is still difficult to learn how to use language properly in cross-cultural communication. Although Chinese students will organize English proficiency tests before they exchange in the United States, this does not mean that they can communicate freely with English American students and guidance teachers without hindrance. The great cultural difference between China and foreign countries leads to different moral baseline. Some of the normal behavior of Chinese people is very impolite to foreigners. When Chinese students first come to foreign countries, they will habitually choose to get along with Chinese students, and gradually understand the way to get along with each other, and then communicate with them actively.

\subsection{Psychological Cause}

Most of the students in the survey are lack self-confidence in English conversation, make a correct evaluation of their own ability and the classroom environment, even in the classroom communication link to actively participate in this situation, if not corrected, will enable students to learn English in a state of stalemate it is difficult to achieve a major breakthrough. When all the unrealistic concepts of learning are in conflict with reality, anxiety arises. For example, some students are confident that they can master a foreign language in a short period of time through careful study. In fact, the language learning process is very complex, such goals are usually difficult to achieve. The students who hold this kind of expectation tend to have unrealistic fantasies about the nature and characteristics of language learning from the beginning, and, of course, tend to go back in vain. Self-concept largely depends on the reflection and evaluation of others, reflecting that evaluation is the information that people get from others, and the information they have will have a greater impact on their behavior. In cross-cultural communication, the students need to act according to the way of keeping the consistency of their own views. If the position is not clear enough, it is easy to influence the cross-cultural communication because of the confusion of their roles.

\subsection{Environmental Causes}

Tense and serious classroom atmosphere will directly bring about a certain degree of psychological anxiety to college students. On the contrary, relaxed classroom atmosphere can reduce the anxiety level of College students. Some foreign students fail to develop the habit of writing in English under the influence of culture, and because of the lack of confidence and the influence of the classroom environment, it is difficult for them to face the English writing correctly. For long-term degree students, it is more important to communicate with American instructors. Because they want to get a degree abroad, it's not just the completion of the course credits, it's so simple, they have to finish their graduation project. Therefore, they need more guidance and help from teachers. Foreign 
students in the foreign classroom is more relaxed mood to feel foreign different from China's classroom atmosphere and teaching methods. While the long-term degree students are more concerned about the results, so the class will be more active speech to get higher normal points. The biggest difference between foreign class and Chinese class is that foreign class is an open class, and the form of teaching is the teaching mode of discussion. Whether Chinese students can freely participate in class discussion is limited by two aspects: English proficiency and professional knowledge. The level of professional knowledge is also influenced by academic language ability. Foreign students with low English proficiency are reluctant to communicate with teachers, and are reluctant to participate in class discussions. The effective communication between teachers and students directly determines the development of the academic level of international students.

\section{Countermeasures of English Learning Anxieties of Chinese Students Studying Abroad}

\subsection{Learn Western Culture}

The relationship between communication and culture is very close, the purpose of communication arrives, must go through a lot of aggregated forms of language and non-language way, the difference between the cultural one will be reflected in cross-cultural communication. There are many differences between Chinese and Westerners, both in business and in daily life. For example, the way of greeting and greeting, Westerners in the formation of the rules of life contacts, compared to the Chinese people in the formation of the habit of language expression, there is a big difference. A chat language is also the age of each other, marriage, and family affection, etc. But Americans and Britons are very disgusted with this kind of greeting. They are trying to interfere in their private lives, their privacy is violated, monitored by the other party, they are willing to accept the topic irrelevant to personal life chat, greeting is the same. The expression of praise and celebration, Chinese common euphemistic and Implicit Verbal Expression of inner feelings, try to free direct discourse about what to say congratulations, people praise; similarly, get the praise of others, is not a direct answer, but with the humble answer. The heart receives praise and joy, but they will not admit it positively, but speak the words of humility, on the contrary, Westerners will not express thanks directly. The great cultural difference between China and the United States is also an important factor that causes the anxiety and uncertainty of Chinese students in cross-cultural communication, thus affecting the effective cross-cultural communication. In the process of intercultural communication, Chinese students are inevitably marginalized because of the weak language and culture. All of these inevitably lead to the anxiety of Chinese students in the process of their self-concept formation. At this time, Chinese students should have a clear self-positioning, timely adjustment of their life and learning state. Only through positive self-affirmation in cross-cultural communication can we influence others and adapt to the culture of other countries. In order to integrate into western culture, Chinese students should first see and experience the mainstream culture, and understand what culture you should integrate into. Different from the traditional Chinese culture in the past years, there are various cultures in the society, which are organically integrated. Therefore, Chinese students do not have to deliberately integrate into all cultures, but should be based on Chinese traditional culture, establish their own correct mainstream concept and their own independent personality, have a clear understanding of themselves, which is the key to reduce the Chinese students' contacts. When Chinese students enter a new environment, they prefer to be with Chinese students and have class together. This is a form of anxiety and uncertainty for Chinese students to avoid communication.

\subsection{Strengthen Emotion Training}

In order to improve college students' English learning, in addition to the need to improve the external environment, the students themselves should also make the necessary efforts to strengthen the heart, to prepare for study. Therefore, college students should do well in the following aspects. A correct understanding of the timeliness of the best thinking, any anxiety is temporary psychological condition, it will not become a long-term psychological quality, not be irreversible on other aspects of the individual. A correct understanding of their own, regardless of whether there is learning English 
only thinking, through the classroom or other environment delivered to each student's information are at the same time, the same, homogeneous, each student has been given equal treatment in the process of learning. No student can achieve perfect performance when he completes his language task, even if the students who have stronger ability will not finish it perfectly, even if the students who are poor in ability will not accomplish nothing. Students into them in the classroom teaching activities, fully prepared, regularly adjust self-assessment by the teachers and students exchange, reduce their anxiety, poor sense etc. The language ability of Chinese students has a great influence on their cross-cultural communication enthusiasm. After the one or two setback, confidence will be hit and the communication with locals will be minimized. Therefore, in order to enable Chinese students to achieve cross-cultural communication effectiveness, they should overcome language barriers and psychological barriers, as much as possible to communicate with the local people.

\subsection{Improve Teaching Environment}

In order to improve the anxiety of college students in English learning and improve the efficiency and effectiveness of English learning, we should first create an environment to reduce and eliminate the influence of external factors. This is because English learning is related to cultural, classroom and other environmental factors. In addition, any student is an independent individual, especially in today's society, their personality is more distinct. This circle can make exchange students get a great sense of security, but too much dependence will have a bad impact on effective cross-cultural communication. Effective cross-cultural communication requires exchange students to come out of anxiety, and as much as possible to reduce their uncertainty when communicating with Americans, so as to carry out effective cross-cultural communication. Therefore, teachers should be aimed at introverted students, encourage them to actively participate in the classroom, so that they can gradually establish their self-confidence, eliminate nervousness. Teachers use group communication teaching mode to relax the students' mood, so that students can have more time to think, prepare and practice, and reduce their anxiety in English conversation. According to Goodey's theory, the number of effective exchanges between residents and locals is positively related to the prediction accuracy of their cultural behaviors, thus reducing their anxiety in different cultural environments. Through the form of cooperative learning, to strengthen students' learning motivation, enhance their self-confidence, realize the charm of communication, the desire to communicate, to experience the success of happiness.

\section{Conclusion}

In the English teaching system for Chinse students learning abroad, listening, speaking, reading and writing are the four necessary courses. However, through the survey, it is found that in these four aspects, most of the Chinese students have the anxiety to some degree. How to eliminate the influence on English learning has become a subject for English learners. This paper makes a survey and analyze the causes of the students' English learning anxiety, and draws some suggestions. Of course, the work of this paper is preliminary, and the study will be long-term and sustainable.

\section{Acknowledgements}

Jiangsu Overseas Research \&. Teaching Program for University Prominent Yong \&. Middle-aged Teachers and Presidents.

Gu Guannan (1981- ), female, Taizhou, Jiangsu Province, China, associate professor, master's degree, Applied Lingustics and English Teaching.

\section{References}

[1] Xu Shuyan, Yang Xianhua. English Learning Anxiety for Adolescent and Its Relation to English Achievement [J]. China Journal of Health Psychology, 2013, 21(9): 1384-1386. 
[2] Liu Yingshuang. An Investigation and Analysis of College Students English Learning Anxiety [J]. Foreign Language and Literature (bimonthly), 2013, 29(2): 174-176.

[3] He Shan. A Study of Foreign Students' Language Anxiety in Learning Chinese [J]. Journal of Yunnan Normal University (Teaching and Research on Chinese As A Foreign Language), 2014, 12(2): 61-69.

[4] Xu Jinfen, Kou Jinnan. A Study on English Learning Anxiety Self - regulation Strategies of College Students [J]. Foreign Language Research, 2015(2): 102-107. 